\title{
Diagnostic Markers for Identifying Sepsis in Patients with Systemic Inflammatory Response Syndrome (SIRS): A Prospective Study
}

\author{
Jana Pavare*, Ilze Grope, Linda Eihvalde and Dace Gardovska
}

Riga Stradins University, Department of Pediatrics, Latvia

\begin{abstract}
Sepsis caused by infection remains a major cause of mortality and morbidity among children. Several inflammatory markers have failed to meet the requirements for early diagnosis of sepsis. We saw the potential value of measuring the total leukocyte count and the inflammatory markers $C$ reactive protein (CRP), procalcitonin (PCT) and interleukin (IL) 6 in patients with SIRS for early identifying of sepsis. Children with SIRS $(n=52)$ were included in a prospective study. Changes in the total leukocyte count and levels of inflammatory markers and their inter-correlations were evaluated in SIRS and sepsis patients at different time points. Sepsis was recognized in $21 \%$ of the SIRS patients. There was a statistically significant difference between PCT and CRP levels in the SIRS and sepsis patient groups. In patients with sepsis, the IL6 level at the outset of the study had a mean value of $476.68 \pm 955.137 \mathrm{pg} / \mathrm{ml}$, which differed significantly from the mean IL6 level in SIRS patients $(51.3 \pm 137.5 \mathrm{pg} / \mathrm{ml})$. The IL6 level in sepsis patients decreased significantly after 24 hours. We conclude that SIRS and sepsis patients differed significantly in respect of changes in CRP, PCT and IL6 levels. In view of the relatively small number of subjects in the sepsis group we can only suggest that special attention should be paid to SIRS patients with elevated levels of those indicators. A continuing search for specific and sensitive inflammatory markers and their combinations in SIRS patients is required so that sepsis can be diagnosed early enough.
\end{abstract}

\section{INTRODUCTION}

Sepsis caused by infection remains a major cause of mortality and morbidity among children in Latvia and throughout the world $[1,2]$. There are more than 42,000 cases of severe sepsis per annum among children in the USA with a mortality rate of $10.3 \%$ [3]. Between 1995 and 2000, 82 children with sepsis were treated in the only tertiary level hospital in Latvia, and $24.4 \%$ of these cases were fatal [4]. Clinical experience and various studies have shown that the most important measure in reducing mortality from sepsis is early identification of the condition and prompt initiation of therapy [5-8]. Diagnosis of sepsis in children is difficult in everyday practice for many reasons: the clinical signs in children are very variable at the start of the infection; microbiological culture results are expected only after 48-72 hours; and false negatives are common. The turning-point in clinical recognition of sepsis is considered to have been the International Sepsis Consensus Conference in the USA in 2002, in which specific clinical definitions of systemic inflammatory response syndrome (SIRS) and sepsis in children were adopted. The major difference in the definition of SIRS between the adults and children was incorporate that the diagnosis of pediatric SIRS requires that temperature or leukocyte abnormalities be present [5].

Laboratory tests are as important as physiological parameters for the early diagnosis of sepsis. We may be close to finding biological markers that will make diagnosis more objective and more reliable than various clinical signs and symptoms. During the last decade, measurement of $\mathrm{C}$

*Address correspondence to this author at the Riga Stradins University, Department of Pediatrics, Latvia; E-mail: jana.pavare@inbox.lv reactive protein (CRP), a good inflammatory marker, has been added to the set of hematological tests (total leukocyte count, neutrophils, band form counts) that have long been used in clinical practice. However, it does not have the specificity required to distinguish viral from bacterial infections. The calcitonin prohormone procalcitonin (PCT) has seldom been used clinically; its level is low in healthy individuals $(<0.5 \mathrm{ng} / \mathrm{ml})$. Levels of procalcitonin rise during bacterial infections but are unchanged during viral infections [9-11].

Since the end of 1990s the role of inflammatory cytokines in modulating the macro-organism's response to infection has been studied, along with the significance of cytokines in early diagnosis and monitoring of sepsis. Interleukin 6 (IL6) has attracted attention as an early inflammatory marker; its levels correlate with the severity and prognosis of sepsis $[12,13]$. IL6 is a proinflammatory cytokine that stimulates both B- and Tlymphocytes and is involved in the induction of fever and in the synthesis of hepatic acute phase protein $[14,15]$.

According to available evidence, several inflammatory markers have failed to meet the requirements for early and reliable diagnosis of sepsis. Study results and trends show that measurements of combinations of biochemical markers offer the best prospects for research on early diagnosis of sepsis. Taking into account the new definition of sepsis in children [5] - systemic inflammatory response syndrome with apparent or confirmed infection - and evaluating the need for effective and rapid laboratory (quantitative) indicators, we saw an approach to studying the early clinical and laboratory diagnosis of sepsis in children.

The aim of this study was investigate the value of measuring changes in total leukocyte count, CRP, PCT and IL6 for the early diagnosis of sepsis in SIRS patients. 


\section{MATERIALS AND METHODOLOGY}

Children with SIRS $(n=52)$ treated in the Children's Clinical University Hospital between January and May 2008 were enrolled in this prospective study. The group of patients enrolled was determined by previous screening of all children with body temperature changes (fever or hypothermia). A screening questionnaire was filled out for each child, and SIRS criteria were evaluated taking account of the values for vital signs and rates appropriate to the child's age group: body temperature, heart rate, respiratory rate and leukocyte count [16]. The study design is given in Fig. (1).

\section{Inclusion Criteria [16]}

1. Presence of at least two of the following four criteria, of which one must be temperature or leukocyte count changes:

- $\quad$ Temperature $>38.5$ or $<36^{\circ} \mathrm{C}$;

- Tachycardia (at least 2 SD above normal age group value) or bradycardia in children < 1 year old (at least 2 SD below normal age group value);

- $\quad$ Respiratory rate $>2 \mathrm{SD}$ above normal age group value;

- Elevated or reduced leukocyte count according to normal age group values, or $>10 \%$ immature neutrophils.

2. Child's age between 7 days and 18 years.

3. Consent of parents for child's participation in the study.

The children were divided into six age groups according to the definitions of the International Sepsis Consensus Conference: newborns (children from the $1^{\text {st }}$ postnatal day to 1 week old), neonates (1 week to 1 month old), infants (1 month to 1 year old), toddler and preschool (2-5 years old), school age (6-12 years old) and adolescent and young adult (13-18 years old).

\section{Exclusion Criteria}

- Antibacterial therapy within the last 48 hours

- Immunodeficiency

- Chronic/terminal liver or kidney illness

- Vaccination within 5 days before the start of the illness

- Any chronic illness that alters CRP levels

- Congenital metabolic defects

- Chromosomal anomalies

- Consent of parents not obtained.

For the patients identified with SIRS a special SIRS study questionnaire was completed. At time 0 and at the 24th and 48th hours of the study, a venous blood sample was drawn from each patient under local anesthesia induced by an EMLA patch. Total leukocyte count and levels of CRP, PCT and IL6 were determined in each sample. CRP level measurement was studied by the latex method (COBAS INTEGRA; Roche professional Diagnostics), the lowest assay sensitivity was $0.085 \mathrm{mg} / \mathrm{L}$. CRP levels $<20 \mathrm{mg} / \mathrm{L}$ in our study were accepted as normal. The BRAHMS PCT-Q immunochromatografic test (Brahms - Diagnostica, Germany) for the semi - quantitative detection of PCT was used. PCT concentrations ranges $<0.5 \mathrm{ng} / \mathrm{ml}, \geq 0.5 \mathrm{ng} / \mathrm{ml}, \geq 2 \mathrm{ng} / \mathrm{ml}$ and $\geq 10 \mathrm{ng} / \mathrm{ml}$ were detected with the help of a reference card The Interleukin 6 (IL6) was determined with the a chemiluminescent immunometric assay Immulite 2000 (Siemens Medical, Germany). The analytical sensivity was 2 $\mathrm{pg} / \mathrm{ml}$. White blood cells and neutrophils were counted on Advia 2120 (Siemens Medical, Germany). All investigations were made immediately. All of the laboratory analyses in this study were carried out in the laboratory of Children Clinical University hospital (Latvia). The following were also determined: the prevalence of sepsis within the SIRS patient population; clinical and demographic data of the SIRS patients; criteria confirming SIRS. Also, the changes in

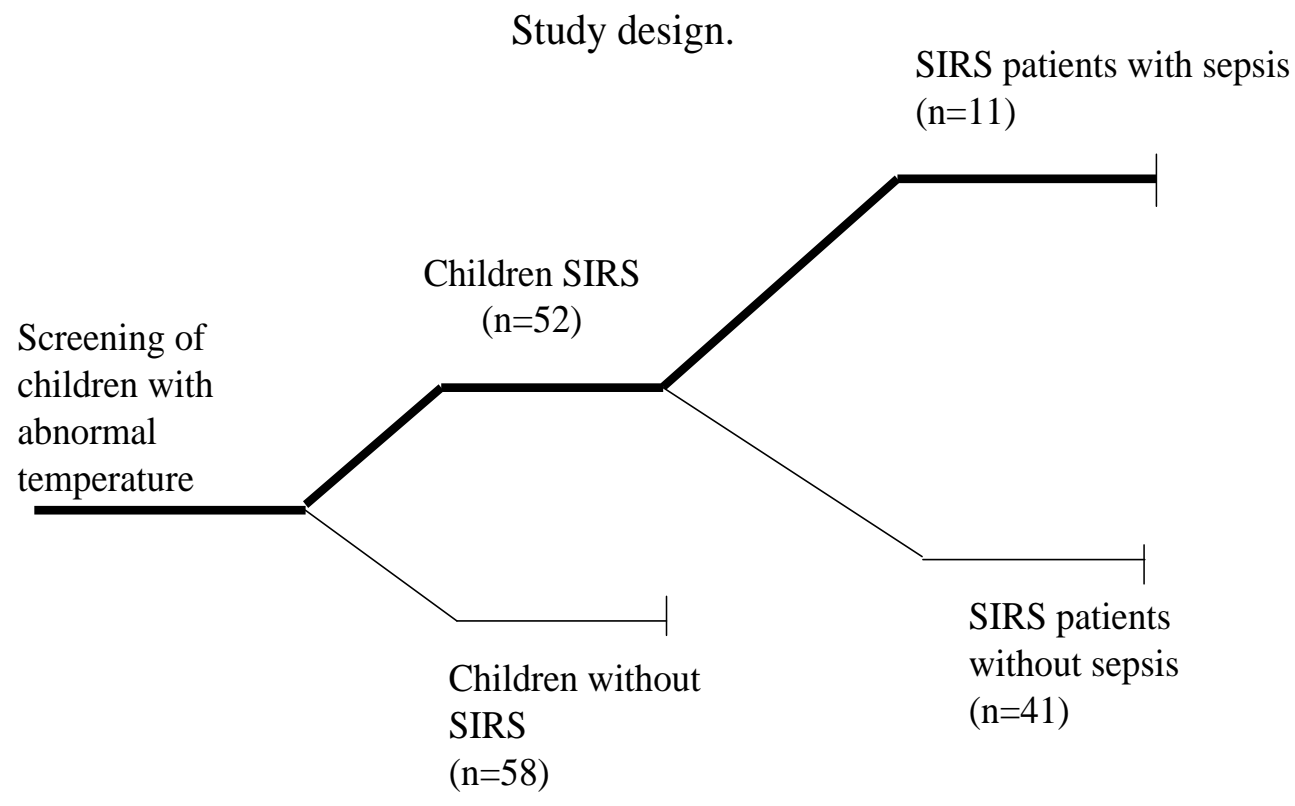

Fig. (1). Study design. 
total leukocyte count and inflammatory marker levels and their inter-correlations were evaluated in the SIRS and sepsis patients at different times during the study. The participation of patients was voluntary. Before the study, each child's parents signed a consent form approved by the Central Medical Ethics Committee. The study data were processed using EPI INFO 2000 and SPSS. For the analysis of patient, data descriptive statistics were used. For continuous variables, normality was checked. An appropriate non - parametric test was chosen, since the data were not distributed normally. Comparisons of continuous variables between groups were applied using the Mann - Whitney and Wilcoxon tests. The chi - square test was used in analysis of categorical variables between groups. Results were presented as numbers (n), percent $(\%)$, means \pm standard deviation and minimum - maximum (min-max). A p value $<0.05$ was considered statistically significant.

\section{RESULTS}

Fifty-two SIRS patients were enrolled in the prospective study; sepsis was recognized in $21 \%(\mathrm{n}=11)$ of them. In none of the sepsis cases was the diagnosis defined in their case history. According to the International Sepsis Consensus Conference definition, SIRS is most often recognized, when patients with changes in body temperature are screened, as fever with respiratory rate increased by more than 2SD above normal age values; this was found in 58\% (n $=30$ ) of our cases. Fever with tachycardia at least $2 \mathrm{SD}$ above normal age values was noted in $54 \%(\mathrm{n}=28)$, while only $40 \%$ of the SIRS patients $(n=20)$ had fever and abnormal count of leukocytes. Hypothermia was not detected. The mean age of the SIRS patients was 6.46 years (minimum 10 months, maximum 17 years 9 months). The median age of the sepsis patients was 8.22 years (minimum 2 years 6 months, maximum 16 years 9 months). The overall analysis of the SIRS and sepsis patients showed that in $94 \%(n=49)$ some infectious disease was diagnosed. Compared to the therapeutic and surgery diagnosis group, SIRS and sepsis were significantly associated with infectious diseases $(\mathrm{p}<0.01)$. In our study infection was proven by two separate positive blood cultures in 50\% of sepsis patients, others had positive findings on clinical examination, imaging and laboratory tests. In our study the source of sepsis was pneumonia, bacterial meningitis, urinary tract infection, soft tissue infection, primary bloodstream infection. Thirty-one percent $(n=13)$ of the children with SIRS and 18\% $(n=2)$ of those with sepsis had concomitant illnesses. The mean day of hospitalization of SIRS patients was the third day of illness (min day 1, max day 14). Sepsis patients were hospitalized earlier - the mean was the second day of illness (min day 1, max day 6). The mean inclusion times were the $4^{\text {th }}$ day of illness for the SIRS patients (min day 1, max day 17) and also for the sepsis patients (min day 2 , max day 17). The mean hospital treatment time for SIRS patients was 7 days $(\min 3$, max 30 days); the corresponding time for the sepsis patients was 12 days ( $\min 7, \max 30$ days). Neither the SIRS nor the sepsis patient groups showed statistically significant sex differences, and the two groups did not differ significantly in the day of hospitalization, duration of hospitalization and inclusion in the study ( $\mathrm{p}>0.05)$ (Table $\mathbf{1})$.

Abnormal count of leukocytes (leukocytosis or leucopenia, according to each age group) were noted in $37 \%$ $(\mathrm{n}=15)$ of the SIRS patients at the outset of the study. CRP over $20 \mu \mathrm{g} / \mathrm{ml}$ was found in $71 \%(\mathrm{n}=29)$, elevated PCT in $39 \%(\mathrm{n}=16)$ and IL6 over $5 \mathrm{pg} / \mathrm{ml}$ in $90 \%(\mathrm{n}=37)$ of the SIRS patients. Results are listed in Table 2. All three inflammatory markers at the outset of the study were elevated in $72.7 \%(\mathrm{n}=8)$ sepsis patients and in $35.7 \%(\mathrm{n}=42)$ SIRS patients. At the outset At the $0^{\text {th }}$ hour of the study there were statistically significant correlations between abnormal count of leukocytes and elevated levels of CRP ( $p<0.01)$, abnormal count of leukocytes and IL6 ( $p<0.05$ ), and CRP and PCT levels $(\mathrm{p}<0.01)$ in SIRS patients.

At time $0,46 \%$ of the SIRS patients with sepsis $(n=5)$ had abnormal count of leukocytes; elevated CRP was seen in $100 \%(\mathrm{n}=11)$ of these patients, PCT was elevated in $73 \%$ $(\mathrm{n}=8)$ and IL6 in 91\% $(\mathrm{n}=10)$ (Table 2). However, the sepsis patients showed no significant correlations between abnormal count of leukocytes and inflammatory marker levels, or among the inflammatory markers.

The PCT concentration was higher in the sepsis patients $18 \%(\mathrm{n}=2)$ had PCT concentrations above $10 \mathrm{ng} / \mathrm{ml}, 18 \%$ $(\mathrm{n}=2)$ in the $2-10 \mathrm{ng} / \mathrm{ml}$ range - than in the SIRS group, where no patient had a PCT concentration above 10 and only $13 \%(\mathrm{n}=5)$ had PCT concentrations in the $2-10 \mathrm{ng} / \mathrm{ml}$ range

Table 1. Clinical and Demographical Data of SIRS and Sepsis Patients

\begin{tabular}{|l|c|c|c|}
\hline \multicolumn{1}{|c|}{ Clinical and Demographical Data } & SIRS Patients $(\mathbf{n}=\mathbf{4 1})$ & Sepsis Patients (n=11) & Statistics \\
\hline \hline $\begin{array}{l}\text { Age } \\
\text { (mean, minimal -maximal) }\end{array}$ & $\begin{array}{c}6.46 \pm 5.9 \\
(10 \text { months }-17 \text { year } 9 \text { months })\end{array}$ & $\begin{array}{c}8.22 \pm 582 \\
(2 \text { year } 6 \text { months }-16 \text { year } 9 \text { months })\end{array}$ & $\mathrm{p}>0.05$ \\
\hline Gender girls/boys (number) & $19 / 22$ & $5 / 6$ & $\mathrm{p}>0.05$ \\
\hline $\begin{array}{l}\text { Day of hospitalization } \\
\text { (mean, minimal -maximal) }\end{array}$ & $3 \pm 2.6(1-14)$ & $4 \pm 2.6(2-11)$ & $\mathrm{p}>0.05$ \\
\hline $\begin{array}{l}\text { Inclusion time in the study } \\
\text { (day of ilness mean, mean -maximal) }\end{array}$ & $4 \pm 3.0(1-17)$ & $12 \pm 7.5(7-30)$ & $\mathrm{p}<0.05$ \\
\hline $\begin{array}{l}\text { Treatment time in the hospital } \\
\text { (mean, minimal -maximal) }\end{array}$ & $7 \pm 5.4(3-30)$ & $18 \%(\mathrm{n}=2)$ & $\mathrm{p}>0.05$ \\
\hline $\begin{array}{l}\text { Concomitant ilnesses } \\
\text { (number/ \% from all patients) }\end{array}$ & $31 \%(\mathrm{n}=13)$ & \\
\hline
\end{tabular}

Data are presented as the absolute number $(\%)$ or the mean \pm standard deviation. 
Table 2. Abnormal Count of Leukocytes and Inflammatory Markers at the Outset of the Study

\begin{tabular}{|c|c|c|c|c|}
\hline Patients Group & $\begin{array}{c}\text { Elevated or Reduced Leukocyte Count } \\
\text { According to Determined Age Group Values } \\
\text { 0 Hour }\end{array}$ & $\begin{array}{c}\text { C Reactive Protein } \\
>20 \mu \mathrm{g} / \mathrm{ml} \\
0 \text { Hour }\end{array}$ & $\begin{array}{l}\text { Procalcitonin } \\
>0.5 \mathrm{ng} / \mathrm{ml} \\
\text { 0 Hour }\end{array}$ & $\begin{array}{l}\text { Interleukin } \\
6>5 \mu \mathrm{g} / \mathrm{ml} \\
0 \text { Hour }\end{array}$ \\
\hline $\begin{array}{l}\text { SIRS patients } \\
\qquad(\mathrm{n}=41)\end{array}$ & $\begin{array}{c}37 \% \\
(\mathrm{n}=15)\end{array}$ & $\begin{array}{c}71 \% \\
(\mathrm{n}=29)\end{array}$ & $\begin{array}{c}39 \% \\
(\mathrm{n}=16)\end{array}$ & $\begin{array}{c}90 \% \\
(\mathrm{n}=37)\end{array}$ \\
\hline $\begin{array}{l}\text { Sepsis patients } \\
\quad(\mathrm{n}=11)\end{array}$ & $\begin{array}{c}46 \% \\
(\mathrm{n}=5)\end{array}$ & $\begin{array}{c}100 \% \\
(\mathrm{n}=11)\end{array}$ & $\begin{array}{c}73 \% \\
(\mathrm{n}=8)\end{array}$ & $\begin{array}{c}91 \% \\
(\mathrm{n}=10)\end{array}$ \\
\hline
\end{tabular}

(Fig. 2). The difference in PCT levels between the sepsis and SIRS patients was statistically significant $(\mathrm{p}<0.05)$.

IL6 was significantly high in the sepsis patients at time 0 of the study - mean $476.68 \pm 955.137 \mathrm{pg} / \mathrm{ml}$, but there was a significant decrease $(\mathrm{p}=0.004,<0.01)$ at 24 hours -mean $42.85 \pm 61.614$ pg/ml (Fig. 3).

In SIRS patients at time 0 the mean IL6 level was mean $51.3 \pm 137.2 \mathrm{pg} / \mathrm{ml}$ (Fig. 4), which was significantly less than the value (mean $476.68 \pm 955.1 \mathrm{pg} / \mathrm{ml}$ ) for the sepsis patients.
The mean level of CRP at time 0 was $136.7 \pm 89.7 \mu \mathrm{g} / \mathrm{ml}$ in the sepsis patients, significantly different $(\mathrm{p}<0.05)$ from the mean level in the SIRS patients - mean $58.8 \pm 56.8 \mu \mathrm{g} / \mathrm{ml}$ (Fig. 5).

\section{DISCUSSION}

To review publications dedicated to issues surrounding SIRS and sepsis, we used the NIH (National Institutes of Health) database. Only a narrow range of research papers have been dedicated to SIRS and sepsis in children. This may be connected to the definitions of SIRS and sepsis in

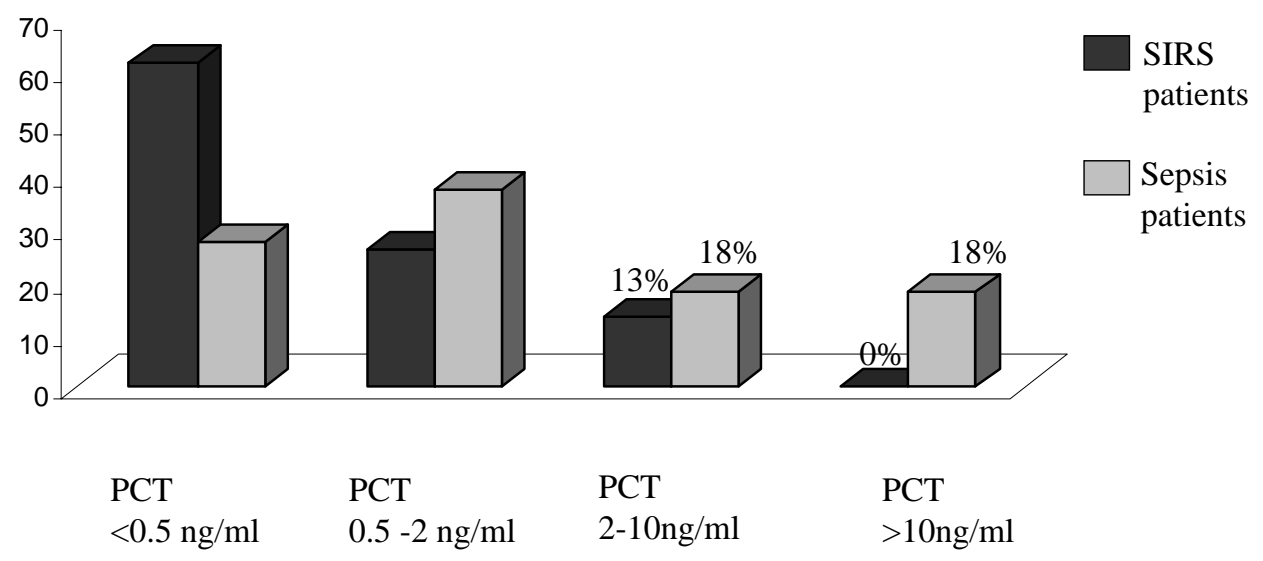

Fig. (2). Changes in procalcitonin (PCT) concentration in SIRS and sepsis patients.

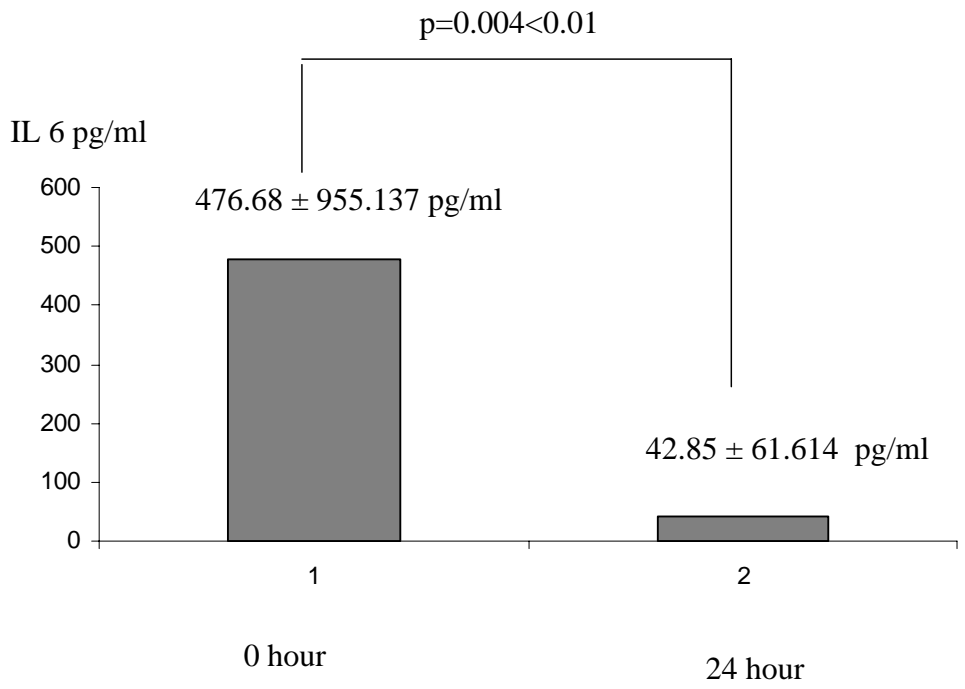

Data are presented as the mean \pm standard deviation.

Fig. (3). Mean levels of interleukin (IL) 6 at the outset in sepsis patients and at 24 hours. 


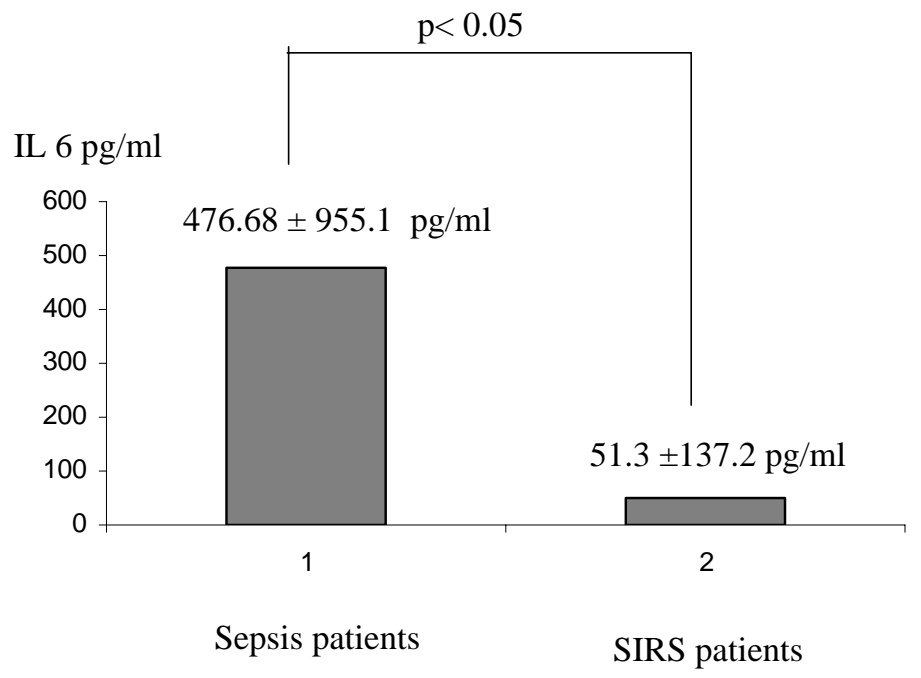

Data are presented as the mean \pm standard deviation.

Fig. (4). Mean levels of interleukin (IL) 6 in SIRS and sepsis patients at the outset of the study.

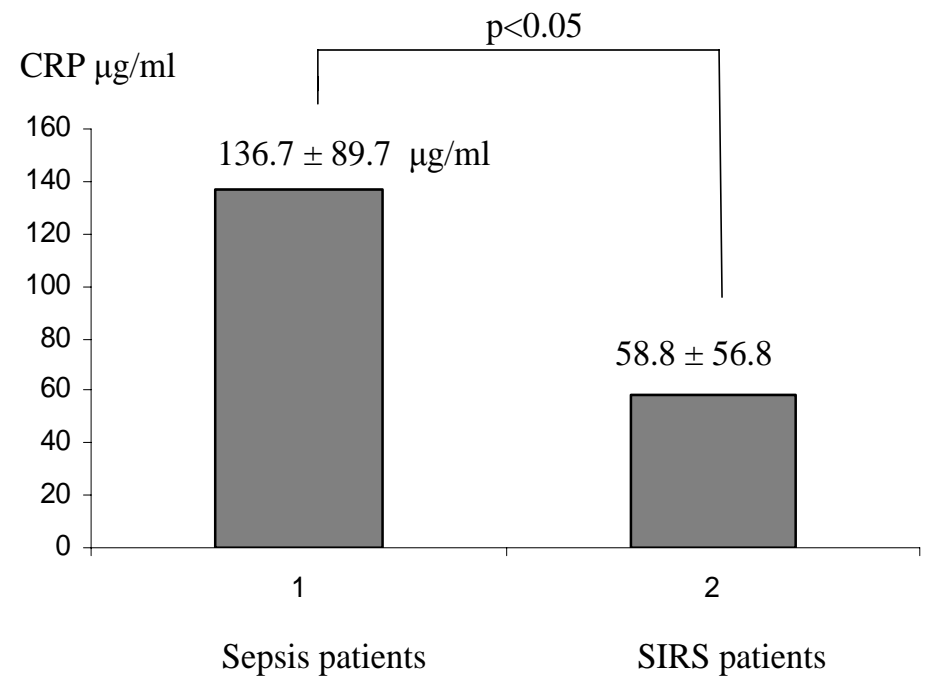

Data are presented as the mean \pm standard deviation.

Fig. (5). Mean levels of $\mathrm{C}$ reactive protein (CRP) in SIRS and sepsis patients at the outset of the study.

children, which have only relatively recently been adopted. Our data are consistent with those in the literature about the age at which children are most prone to developing SIRS and sepsis. In our study the mean age of SIRS patients was 6.46 years, but that of sepsis patients was 8.22 years; the age most frequently mentioned in the literature is 24 months [17]. In accordance with the International Sepsis Consensus Conference definition, both our study and the literature data show that SIRS and sepsis are most frequently found in children between 2 and 8 years old. Twenty-one percent $(n=11)$ of the children with SIRS developed sepsis in our study, which broadly corresponds to other studies: $26 \%$ of adults with SIRS developed sepsis in a study by Rangel-Fausto [18], and $23 \%$ of children developed sepsis in the Proulx study [19]. In our patients, SIRS was confirmed according to the International Sepsis Consensus Conference's definition by fever, with changes in breathing rate of more than 2 SD above the age-normal value in $58 \%(\mathrm{n}=30)$ of cases; in the literature this combination has been noted in $48 \%$ of cases [20]. Fiftyfour percent $(n=28)$ of the children in our study had fever with tachycardia more than $2 \mathrm{SD}$ above the age-normal values, and this was also observed in $85 \%$ of the children in the Carvalho study [20]. Forty percent of the patients $(n=20)$ in the Children's Clinical University Hospital had SIRS comprising fever and abnormal count of leukocytes. This was noted in $78 \%$ in the literature data; the percentage difference could be explained by the relatively small number of patients in our study. Thirty-one percent $(n=13)$ of the children with SIRS had some concomitant illness $(\mathrm{p}<0.010)$, which again corresponds to published numbers: $36 \%$ of the children with SIRS had some concomitant illness in [20]. In our study, SIRS patients showed no significant sex differences, which also agrees with literature data [20].

The aim of our study - to identify diagnostic markers that would allow sepsis patients to be distinguished and recognized early in a population of SIRS patients - has only partly 
been achieved. Our sepsis patients showed no statistically significant differences in CRP, PCT or IL6 levels at the outset of the study. Nor was there a statistically significant correlation between the inflammatory markers and changes in total leukocyte count in the sepsis patients. This is entirely consistent with data from other studies, and the search for more consistent inflammatory markers or combinations of markers for the early diagnosis of sepsis continues [14, 15, 21, 22].

PCT levels are below the limits of detection in healthy individuals, and they are elevated when a bacterial infection is present. In our study, 39\% $(n=16)$ of the SIRS patients and $73 \%(n=8)$ in the sepsis group had elevated PCT levels. However, several studies suggest that PCT provides less diagnostic accuracy than previously supposed [22-25].

The results of our study match literature data in respect of the correlation between PCT level and intensity of inflammation [20]. The extent to which the PCT concentration is elevated may possibly be a useful laboratory tool for recognizing sepsis patients, because even at the beginning of the illness $18 \%(\mathrm{n}=2)$ of the sepsis patients had PCT concentrations above $10 \mathrm{ng} / \mathrm{ml}$ and $18 \%(\mathrm{n}=2)$ had PCT in the $2-10 \mathrm{ng} / \mathrm{ml}$ range. These results correspond with those found by Hatherill and Rey $[11,26]$ (patients with localized bacterial infections and sepsis had PCT $>2 \mathrm{ng} / \mathrm{ml}$ ) and with the data mentioned by Guven [27] (significantly elevated changes in PCT in the early stages of disease indicate a greater probability that sepsis will develop).

The levels of the inflammatory cytokine IL6 at the outset of the study showed statistically significant differences between SIRS and sepsis patients: IL6 was markedly higher in sepsis patients - its median level was $53.10 \mathrm{pg} / \mathrm{ml}$ (mean $476.68 \mathrm{pg} / \mathrm{ml}$ ) - than in SIRS patients, where the median level was $21.10 \mathrm{pg} / \mathrm{ml}$ (mean $31.70 \mathrm{pg} / \mathrm{ml}$ ). These results match those of other studies analyzing data from intensive care unit, facial-maxillary surgery, general surgery and neonatal age patients with SIRS and sepsis [22, 28-33]. The IL6 levels in sepsis patients decreased sharply and significantly at 24 hours $(\mathrm{p}=0.004<0.01)$ from the median value of $53.10 \mathrm{pg} / \mathrm{ml}$ to $25.30 \mathrm{pg} / \mathrm{ml}$. Similar results have also been obtained in other studies [32], confirming the assumption that IL6 is an early inflammatory marker, the level of which decreases sharply if appropriate therapy is initiated.

The statistically significant $(\mathrm{p}<0.05)$ differences in CRP that we observed between SIRS and sepsis patients have also been found in other studies [21, 22]. However, the aforementioned failure of CRP to distinguish between viral and bacterial infections must be considered; moreover, CRP may be elevated in various neonatal pathological states (asphyxia, interventricular hemorrhaghia etc.), and in rheumatological and malignant processes.

We suggest running a specific medical personnel training on clinical recognition of the first "gold" hours of sepsis by systematically and daily search of SIRS criteria in patients. Such activity would improve detecting of sepsis in SIRS patients and possibly could be cost effective by decreasing laboratory costs.

\section{CONCLUSIONS}

Patients with systemic inflammatory response syndrome (SIRS) and sepsis differed significantly in changes in levels of $\mathrm{C}$ reactive protein (CRP), procalcitonin (PCT) and interleukin (IL) 6, so those inflammatory indicators could be used to identify sepsis patients. In view of the relatively small number of subjects in the sepsis group, current evidence only enables us to suggest that particular attention should be paid to SIRS patients with elevated levels of above-mentioned inflammatory indicators, and that those patients should be treated as a high risk population for developing sepsis.

There is a need for a continuing search for new, specific and sensitive inflammatory markers and combinations of markers in SIRS patients that will enable sepsis to be diagnosed early.

\section{ACKNOWLEDGEMENTS}

The authors acknowledge the National Research Programme in Medicine "Multi-disciplinary research consortium on major pathologies threatening the life expectancy and quality of life of the Latvian population".

\section{REFERENCES}

[1] Proulx F, Fayon M, Farrell CA, Lacroix J, Gauthier M. Epidemiology of sepsis and multiple organ dysfunction syndrome in children. Chest 1996; 109: 1033-7.

[2] Watson RS, Carcillo JA. Scope and epidemiology of pediatric sepsis. Pediatr Crit Care 2005; 6 (Suppl 3): 3-4.

[3] Watson RS, Carcillo JA, Linde-Zwirble WT, Clermont G, Lidicker J, Angus D. The epidemiology of severe sepsis in children in the United States. Am J Respir Crit Care Med 2003; 167: 695-701.

[4] Gardovska D, Laizāne G, Grope I. Sepsis outcomes and early diagnostic peculiarities in tertiary level Children's hospital in Latvia. Riga Stradiņš University Scientific Proceedings 2001; pp. 77-83.

[5] Randolph AG. The purpose of the 1st international sespsi forum on sepsis in infants and children. Pediatr Crit Care Med 2005; 6 (Suppl 3): S1-S2.

[6] Brilli RJ, Goldstein B. Pediatric sepsis definitions: past, present, future. Pediatr Crit Care Med 2005; 6(Suppl 3): 6-8.

[7] Mishra K, Jacobs SE, Doyle LW, Garland SM. Newer approaches to the diagnosis of early onset neonatal sepsis. Arch Dis Child Fetal Neonatal Ed 2006; 91(3): F208-12.

[8] Hugonnet S, Sax H, Eggimann P. Nosocomial blood stream infection and clinical sepsis. Emerg Infect Dis 2004; 10: 76-81.

[9] Guven H, Altintop L, Baydin A, et al. Diagnostic value of procalcitonin levels as early indicator of sepsis. Am J Emerg Med 2002; 20 (3): 202-6.

[10] Casado-Flores J, Blanco - Quiros A, Asesnsio J, Arranz E, Garrote J, Nieto M. Serum procalcitonin in children with suspected sepsis. A comparison with $\mathrm{C}$ reactive protein and neutrophil count. Pediatr Crit Care Med 2003; 4: 190-5.

[11] Hathrill M, Tibby SM, Sykes K, Turner C, Murdoch IA. Diagnostic markers of infection: comparison of procalcitonin with $\mathrm{C}$ reactive protein and leucocyte count. Arch Dis Child 1999; 81: 417-21.

[12] Dahmet MK, Randolph A, Viatli S, Quasney MQ. Genetic polymorphisms in sepsis. Pediatr Crit Care Med 2005; 6(Suppl 3): 6173.

[13] Ng PC, Lam HS. Diagnostic markers for neonatal sepsis. Curr Opin Pediatr 2006; 18: 125-31.

[14] Ng PC, Li K, Wong RP. Proinflammatory and anti - inflammatory cytokine responses in preterm infants with systemic infections. Arch Dis Child Fetal Neonatal Ed 2003; 88: F209-13.

[15] Carcillo JA, Planquois JS, Goldstein B. Early markers of infection and sepsis in newborns and children. Adv Sepsis 2006; 4: 118- 25.

[16] Goldstein B, Giroir B, Randolph A; and the members of the International Consensus Conference on Pediatric Sepsis. International pediatric sepsis consensus conference: Definitions for sepsis and organ dysfunction in pediatrics. Pediatr Crit Care Med 2005; 6(Suppl 3): 2-8.

[17] Carvalho PRA, Feldens L, Seitz EE, Rocha T, Soledade M, Trotta A. Prevalence of systemic inflammatory syndromes at a tertiary pediatric intensive care unit. J Pediatr (Rio de Janiero) 2005; 81: 2. 
[18] Rangel-Frausto MS, Pittet D, Costigan M, Hwang T, Davis SC, Wenz RP. The natural history of systemic inflammatory response syndrome (SIRS): a prospective study. JAMA 1995; 273: 117-23.

[19] Proulx F, Fayon M, Farrell CA. Epidemiology of sepsis and multiple organ dysfunction syndromes in children. Chest 1996; 109: 1033-7.

[20] Carvalho PRA, Feldens L, Seitz EE. Prevalence of systemic inflammatory syndromes at a tertiary pediatric intensive care unit. $\mathrm{J}$ Pediatr 2005; 81: 2-8.

[21] Kocabas E, Sarikcioglu A, Aksaray N, Seydaaaaoglu. Role of procalcitonin, $\mathrm{C}$ reactive protein, interleukin-6, interleukin-8 and tumor necrosis factor alfa in the diagnosis of neonatal sepsis. Turkish J Pediatr 2007; 49: 7-20.

[22] Gaini SH, Koldkjaer OG, Pedersen C, Pedersen SS. Procalcitonin, lipopolysaccharide-binding protein, interleukin 6 and $C$ reactive protein in community acquired infections and sepsis: a prospective study. Crit Care 2006; 10(R53): 1-10.

[23] Pacvinik-Arnol M, Hojker S, Deganc M. Lipopolysaccharidebinding protein in critically ill neonates and children with suspected infection: comparision with procalcitonin, interleukin 6 and C reactive protein. Intensive Care Med 2004; 30: 1454-60.

[24] Gaini Sh, Koldkjaer OG, Moller HJ, Pedersen C, Pedersen SS. A comparison of high - mobility group box 1 protein, lipopolisaccharide-binding protein and procalcitonin in severe community acquired infections and bacteraemia: a prospective study. Crit Care 2007; 11(R76): 1-10.

[25] Thayyil S, Shenoy M, Hamaluba M, Gupta A, Frater J. Is procalcitonin is useful in early diagnosis of serious bacterial infections in children? Acta Pediatr 2005; 94: 155-8
[26] Rey C, Los Arcos M, Concha A, et al. Procalcitonin and C-reactive protein as markers of systemic inflammatory response syndrome severity in critically ill children. Intensive Care Med 2007; 33: 47784.

[27] Guven H, Altintop L, Baydin A, Esen S, Aygun D. Diagnostic value of procalcitonin levels as an early indicator of sepsis. Am J Emerg Med 2002; 20: 202-6.

[28] Mokart D, Merlin M, Sannini A. Procalcitonin, interleukin 6 and systemic inflammatory response syndrom (SIRS): early markers of postoperative sepsis after major surgery. Br J Anaesth 2005; 94: 767-73.

[29] Miyaoka K, Iwase M, Suzuki R, et al. Clinical evaluation of circulating interleukin-6 and interleukin-10 levels after surgery induced inflammation. J Surg Res 2005; 125: 144-50.

[30] Silveira RC, Procionoy RS. Evaluation of interleukin-6, tumor necrosis factor-alpha and interleukin- 1 beta for early diagnosis of neonatal sepsis. Acta Paediatr 1999; 88: 647-50.

[31] Oda S, Hirasawa H, Shiga H, Nakanishi K, Matsuda K, Nakamua M. Sequential measurements of IL-6 blood levels in patients with systemic inflammatory response syndrome (SIRS)/sepsis. Cytokine 2005; 29: 169-75.

[32] Pan DJ, Chen D, Li Y. Serum procalcitotin and interleukin-6 levels may help to differentiate systemic inflammatory response of infectious and non - infectious origin. Chin Med J (Eng) 2003; 116: 53842 .

[33] Riche FC, Cholley BP, Panis YH, Laisne MJ, Briard CG, Graulet AM. Inflammatory cytokine response in patients with septic shock secondary to generalized peritonitis. Crit Care Med 2000; 28: 4437.

() Pavare et al.; Licensee Bentham Open.

This is an open access article licensed under the terms of the Creative Commons Attribution Non-Commercial License (http://creativecommons.org/licenses/by$\mathrm{nc} / 3.0 /$ ) which permits unrestricted, non-commercial use, distribution and reproduction in any medium, provided the work is properly cited. 